\title{
SBR 4/2004 SPECIAL ISSUE
}

\section{EDITORIAL}

In September 2003, the German Economic Association of Business Administration, GEABA e.V., organized the IV. Symposium on the Economic ANALYsis of THE Firm at the Johann Wolfgang Goethe-University Frankfurt am Main. The aim of these annual conferences is to serve as a forum to foster interdisciplinary application and development of an economic approach to problems in business administration. The papers given at this conference used instruments and methods of industrial economics, game theory, empirical economics, experimental designs, new institutional economics, and economic psychology to study business problems. Research issues focused on various fields, such as finance, corporate policy, internal or intrafirm organisation, accounting, and strategic management.

This special issue includes three articles based on presentations at the conference and the remarks of the assigned discussants that we consider as a value added of this publication. The articles in this issue focus on auction markets, financial markets and credit risk. The analyses are analytical, empirical, or both. They are indicative of the variety of interesting research issues and economics-oriented methodologies covered by the GEABA conference.

In the next issue of Schmalenbach Business Review, there will be two more articles and the discussions from the conference. All published papers underwent the standard referee process at Schmalenbach Business Review.

The first article in this issue is by Martin Beckmann, who gives an answer to the phenomenon that in some auctions, sellers bid for their own items. In the theoretical part, the author applies a search model to the auction context, in which the owner of an item that is up for sale searches for a price offer that is acceptable to him. The comparative statics of the search model allow the author to derive testable implications on the seller's bidding strategy. In the empirical part of the article, Beckmann uses data from German auction houses to provide evidence for his theoretical implications. Bernd Frick discusses this article.

The second article empirically analyzes the role of the venture capitalist in financing young and innovative firms. Using data from firms listed on the Neuer Markt in Germany, David Audretsch and Erik Lehmann examine whether debt and equity capital are complements or substitutes in financing high-tech growth. They find evidence for the hypothesis that innovative firms are more likely to be financed by venture capitalists than by banks. Peter Witt comments on this article.

The third article is by Udo Broll, Gerhard Schweimayer, and Peter Welzel. The authors study the use of credit derivatives and macro derivatives as instruments that a large commercial bank can use to hedge credit risks. The authors distinguish between the probability of a credit default and the loss if there is a default, and they derive separability results and hedging rules for the optimal bank strategy. They also discuss how bank-specific macro derivatives could be optimally 
designed from financial products on common macroeconomic indices. Thomas Hartmann-Wendels is the discussant of this article.

The local organizer of the IV. Symposium, Prof. Dr. Reinhard H. Schmidt and his team, as well as the sponsors the Ehlerding Stiftung, Dresdner Bank AG, and International Project Consult $\mathrm{GmbH}$, deserve thanks for making this conference a success. The members of the scientific advisory board of the GEABA and the conference discussants handled the referee process and the discussion of the conference, and without their work this symposium would not have been possible. Finally, we thank the anonymous reviewers of the Schmalenbach Business Review.

PETER-J. JOST

ALFRED WAGENHOFER

Special Issue Editors 